\title{
Can Hydroxychloroquine Cause G6PD-Related Hemolysis? A Case Study
}

\author{
Khaldun Obeidat ${ }^{\mathrm{a}}$ Mohamed A. Yassin ${ }^{\mathrm{b}}$ \\ aMedical Education Department, Hamad Medical Corporation/Hamad General Hospital, Doha, Qatar; ${ }^{\text {bHematology }}$ \\ Department, Hamad Medical Corporation/National Center for Cancer Care \& Research, Doha, Qatar
}

\begin{abstract}
Keywords
Hydroxychloroquine · COVID-19 · Glucose-6-phosphate dehydrogenase $\cdot$ SARS-CoV-2 $\cdot$ Hemolysis
\end{abstract}

\begin{abstract}
During the pandemic of COVID-19, which started in December 2019, hydroxychloroquine, the drug which was first introduced as antimalarial medication, was widely used to treat this new viral infection, and it was reported in the literature as a safe drug for use in patients with G6PD deficiency; here, we report a 64-year-old male who was started on hydroxychloroquine as treatment for COVID-19 that led to hemolysis, and further investigation showed that the patient is deficient for glucose-6-phosphate dehydrogenase.
\end{abstract}

C 2020 The Author(s).
Published by S. Karger AG, Basel

\section{Background}

Glucose-6-phosphate dehydrogenase (G6PD) deficiency is a heritable disorder due to genetic defect in the $\mathrm{RBC}$ enzyme G6PD. It was described for the first time in the trials of primaquine for the treatment of malaria in the 1920s. Without this enzyme, oxidative stressors lead to excessive free radicals formation that leads to RBC destruction.

G6PD deficiency is the most common enzymatic disorder of RBCs with a global prevalence of $4.9 \%$ [1], and the gene for this enzyme is located in the $\mathrm{X}$ chromosome, which is why males are affected more frequently than females; however, females can be affected if they are heterozygous or homozygous for this disorder [2]. Too many G6PD variants have been discovered, and the disease severity varies from 1 variant to other; the 2 most common variant types include the Mediterranean variant, which is prevalent in Europe, Asia, and northern India, and it is considered the sever form of this disorder, and another mild form, the African variant, which is prevalent among African people, including African Americans [3, 4].

G6PD deficiency can be asymptomatic or it can present at an early age as exacerbated neonatal jaundice, or it can present as acute hemolytic anemia after exposure to oxidative injury such as medications, acute illness, and certain food, and it will be manifested as jaundice, pallor, dark urine, or back pain which depends on the severity of hemolysis which is related to the patient's G6PD genotype and the magnitude of enzymatic deficiency. That is why some patients may develop sever hemolytic episodes and others will have mild subclinical attacks of hemolysis; in addition to that, the timing of hemolysis may vary depending on the precipitating event, as it can range from hours like with fava beans to several days like with primaquine [2].

G6PD deficiency should be considered in every patient who develops hemolysis after taking new medication, with a family history of G6PD deficiency, or with unexplained prolonged neonatal hyperbilirubinemia, and the karger@karger.com www.karger.com/dmj

Karger $\stackrel{\text { ' }}{5}$

BOPEN ACCESS
(C) 2020 The Author(s)

Published by S. Karger AG, Basel

This article is licensed under the Creative Commons AttributionNonCommercial-NoDerivatives 4.0 International License (CC BYNC-ND) (http://www.karger.com/Services/OpenAccessLicense) Usage and distribution for commercial purposes as well as any distribution of modified material requires written permission.
Khaldun Obeidat

Medical Education, Hamad Medical Corporation

Al Rayan Street

Doha 3050 (Qatar)

dr.khaldun.obeidat@gmail.com 


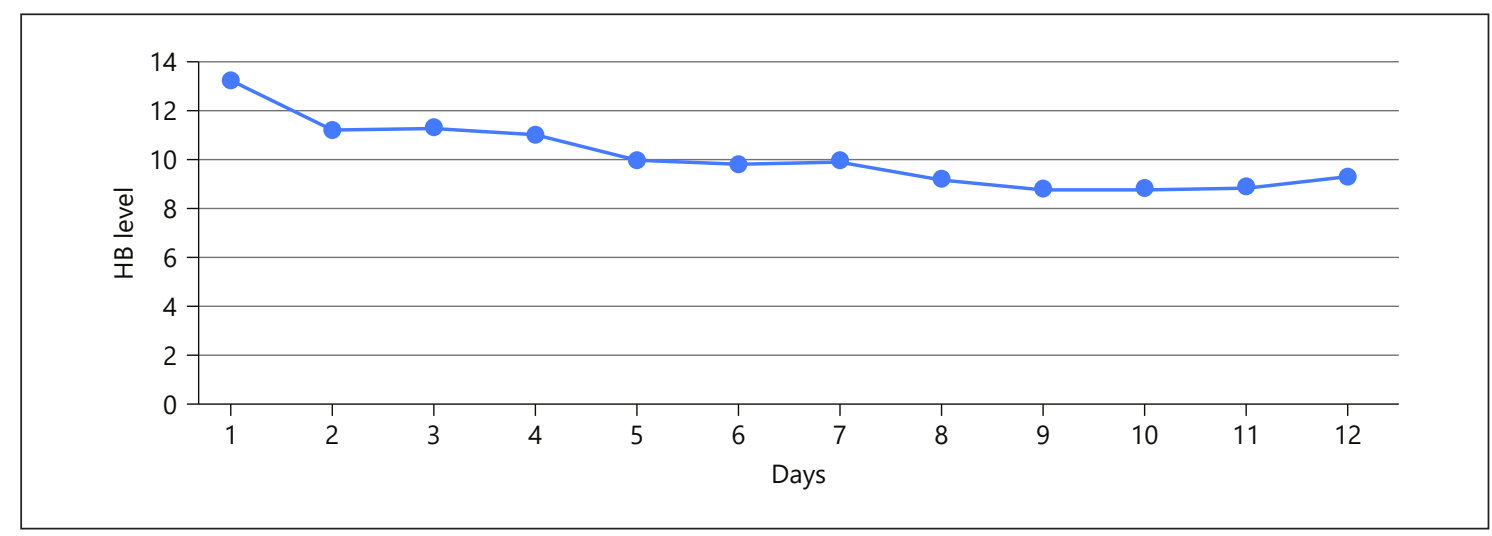

Fig. 1. This figure illustrates the drop in HB level with time after starting hydroxychloroquine, and it shows mild improvement after discontinuation of the drug at day 10. HB, hemoglobin.

laboratory results in this condition will show mild to severe anemia, increase in retics count, increase in indirect bilirubin, and LDH with low or absent haptoglobin; another typical feature is the presence of "bite cells" or denatured hemoglobin "Heinz bodies" in the blood film; the treatment of this condition depends on the severity of hemolysis and education regarding the importance of avoiding any agent which may induce oxidative stress [5].

\section{The Case}

This is the report on a 64-year-old male patient, a known case of diabetes mellitus, hypothyroidism, and hypertension which had been diagnosed a few years prior to this presentation, who presented with cough and fever; on physical exam, the patient was hemodynamically stable, saturating $97 \%$ on room air, and the chest exam was concerning for bilateral crackles. Further evaluation including chest X-ray showed bilateral infiltrate, and the patient tested positive for coronavirus disease 2019 (COVID-19); other laboratory tests including $\mathrm{CBC}$ showed WBC $5.8 \times 10^{3}$, an HB level of $13.2 \mathrm{~g} / \mathrm{dL}$, and PLT at $183 \times 10^{3}$ with normal liver and kidney function, so the patient was admitted as a case of COVID-19 pneumonia, and he was started on hydroxychloroquine (HCQ), azithromycin, ceftriaxone, oseltamivir, and lopinavir/ritonavir, and his home medications were resumed, which included levothyroxine, losartan, and basal-bolus (glargine/aspart) insulin for blood sugar control.

During hospitalization, the patient started to have a drop in hemoglobin level, so an investigation was made that showed an $\mathrm{HB}$ level of $11.3 \mathrm{~g} / \mathrm{dL}$ with normal WBC and PLT and retics count of $119 \times 10^{3}$ (50-100); peripheral smear showed moderate normochromic, normocytic anemia with few hypochromic RBCs, few ovalocytes, few spherocytes, and mild rouleaux formation with mild neutrophilic leukocytosis with mild absolute lymphopenia, total bilirubin at $41 \mu \mathrm{mol} / \mathrm{L}(0-21 \mu \mathrm{mol} / \mathrm{L})$, direct bilirubin at 19.6 $\mu \mathrm{mol} / \mathrm{L}(0-5 \mu \mathrm{mol} / \mathrm{L}), \mathrm{LDH}$ at $352 \mathrm{U} / \mathrm{L}(135-225)$, and a G6PD level of 14 (224-517) with normal folate and vitamin B12, and el- evated ferritin levels as acute phase reactants. Due to these laboratory abnormalities, the patient was diagnosed with hemolysis secondary to G6PD deficiency, but as the bleeding was minimal and for patient benefits, he was continued on HCQ to complete the 10 days; during this time, his $\mathrm{HB}$ continued to drop, and after completion of the treatment time, his HB level started to increase again.

\section{Discussion}

In 1955, HCQ was approved for the first time for medical use in the USA [6], and it is one of the most commonly prescribed medications in the USA with 5 million prescriptions in 2017 [6]; it is classified as an antimalarial drug; however, it is frequently used to treat autoimmune disease like lupus erythematosus, and it used as off-label for the treatment of COVID-19, dermatomyositis cutaneous disease, porphyria cutanea tarda, primary Sjögren syndrome, Q fever (Coxiella burnetii), and sarcoidosis [7]. It has a wide range of side effects, and it affects most of the body organs, for example, retinopathy; dermatological conditions like alopecia and bullous rash; endocrine and metabolic conditions like severe hypoglycemia and weight loss; gastrointestinal conditions like diarrhea, nausea, and vomiting; hepatic conditions like abnormal liver function tests; hypersensitivity conditions like angioedema; immunologic conditions like drug reaction with eosinophilia; nervous system conditions like ataxia and dizziness; neuromuscular and skeletal conditions like myopathy; respiratory conditions like bronchospasm; cardiovascular conditions like cardiomyopathy and prolonged QT interval on ECG; and hematologic and oncologic conditions like agranulocytosis, anemia, aplastic anemia, bone marrow failure, leu- 
kopenia, thrombocytopenia, and hemolysis in patients with D6PD deficiency.

Despite the warning by the manufacturing company regarding the association between HCQ and hemolysis in G6PD-deficient patients, this drug was reported in the literature as a safe drug; in 1 retrospective study which was carried out at the Duke University Medical Center on rheumatology patients published in 2017, they found 11 patients who were tested deficient for the enzyme G6PD and were treated with HCQ; there were no reports of hemolysis in more than 700 months of HCQ exposure among these 11 G6PD-deficient patients [8]. However, hemolysis due to HCQ was reported in 1 case which was published in April 2020 of a 68-year-old male who was started on HCQ for the treatment of COVID-19 that led to severe hemolysis, and the HB level dropped from 12 to $6.5 \mathrm{~g} / \mathrm{dL}$ few days after starting the treatment $[9,10]$.

In our case, the patient's HB level was within the normal level, and after he was started on HCQ $400 \mathrm{mg}$ BID for 1 day then $400 \mathrm{mg}$ daily for 9 days as per our hospital treatment protocol for COVID-19, his HB level was dropping slowly as illustrated in (Fig. 1) and we excluded all other causes for drop in $\mathrm{HB}$; in addition to that, his $\mathrm{HB}$ level started to improve after stopping the drug, which was after completion of the treatment course, which is 10 days.

\section{Conclusion}

HCQ is reported as a safe drug for use in patients with G6PD deficiency, but with the emerging pandemic of COVID-19 and the increased use of it especially in areas with high prevalence of G6PD deficiency, physicians should be more careful with the use of HCQ; in addition to that, a larger study is needed to answer the question of safety and to clarify the need for screening before starting this drug.

\section{Acknowledgement}

We thank the Internal Medicine Residency Program Research group at Hamad Medical Corporation for scientific support.

\section{Statement of Ethics}

Informed consent was obtained from the patient during hospitalization, and the case was approved by the Hamad Medical Corporation Medical Research Center and Institutional Review Board.

\section{Conflict of Interest Statement}

The authors have nothing to disclose.

\section{Funding Sources}

This article will be funded by the Qatar National Library.

\section{Author Contributions}

K.O.: writing and editing of the manuscript, literature review, and clinical management. M.A.Y.: writing and editing and clinical management.

\section{References}

1 Nkhoma ET, Poole C, Vannappagari V, Hall SA, Beutler E. The global prevalence of glucose-6-phosphate dehydrogenase deficiency: a systematic review and meta-analysis. Blood Cells Mol Dis. 2009;42:267-78.

2 Beutler E, Duparc S. Glucose-6-phosphate dehydrogenase deficiency and antimalarial drug development. Am J Trop Med Hyg. 2007;77(4):779-89.

3 Beutler E. G6PDH: population genetics and clinical manifestations. Blood Rev. 1996;10: 45-52.

4 Ashley EA, Recht J, White NJ. Primaquine: the risks and the benefits. Malar J. 2014;13:418.
5 Christensen RD, editor. Hematologic problems of the neonate. Saunders; 2000.

6 The American Society of Health-System Pharmacists. 20 March 2020. Archived from the original on 20 March 2020. Retrieved 20 March 2020.

7 "Hydroxychloroquine Sulfate: Drug Usage Statistics". ClinCalc. Retrieved 7 April 2020.

8 Mohammad S, Clowse MEB, Eudy A, Criscione-Schreiber L. Hydroxychloroquine is not associated with hemolytic anemia in glucose-6-phosphate dehydrogenase (G6PD) deficient patients. Arthritis Rheumatol. 2016; 68(suppl 10).
9 Beauverd Y, Adam Y, Assouline B, Samii K. COVID-19 infection and treatment with hydroxychloroquine cause severe haemolysis crisis in a patient with glucose-6-phosphate dehydrogenase deficiency. Eur J Haematol. 2020 Sep;105(3):357-9.

10 Sasi S, Yassin MA, Nair AP, Al Maslamani MS. A case of COVID-19 in a patient with asymptomatic hemoglobin D thalassemia and glucose-6-phosphate dehydrogenase deficiency. Am J Case Rep. 2020 Jul 22;21: e925788. 